\section{THE FIRST SUCCESSFUL RESECTION OF THE THORACIC PORTION OF THE ESOPHAGUS FOR CARCINOMA}

\section{PRELIMINAIRY REPOR'T *}

FRANZ TOREK, A.M., M.D.

Surgeon to the German Hospltal and the New York SkIn and Cancer Hospital, Adjunct l'rofessor of Surgery in the New York Postgriduate Medical School

\section{NEW YORK}

The resection of the thoracic portion of the esophagus for carcinoma has been one of the greatest problems of modern surgery. A number of careful investigators have declared their standpoint in this matter to be that operations for carcinoma of the esophagus should be undertaken only if the new growth is either high up near the neck or low down where an anastomosis with the stomach can be made, but that the growths in the middle portion of the esophagus are not removable.

The reasons for excluding these cases from the realm of operative interference were, first, the inaccessibility of that portion of the esophagus which passes underneath the arch of the aorta, and, secondly, the danger of injuring the pneumogastric nerves which in that location branch in front of the esophagus like a plexus. Division of both pneumogastric nerves at a place before they reach the heart causes instant death, and at operations in that region it has been repeatedly observed that tugging at a vagus, or pinching it, is promptly followed by collapse in the pulse which persists until death sets in. Finally, the uncertainty of the closure of the upper stump of the esophagus and the consequent infection of the pleural cavity have been a great source of danger after resection of any part of the esophagus where an anastomosis cannot be made. The leakage from that stump is undoubtedly due to the tension in the esophagus from swallowed saliva. Every contraction of the constrictors of the pharynx temporarily increases the tension in this blind pouch, until the suture finally is unable to withstand the pressure from' within.

Statistics show that carcinoma of the esophagus is most frequently found in the middle third, the location in the lower third coming next, while cases in the upper third are comparatively rare. On the other hand, metastases are found most frequently with those situated in the lower third, near the cardia. Since, therefore, the carcinomas at the cardia are not only numerically less frequent than those in the middle third, but are also more frequently associated with metastases and are therefore incurable, the most important problem in cancer of the esophagus is that of extirpating the carcinomas in the middle portion, the very ones that Sauerbruch and others have told us should be left alone.

In an operation performed at the German Hospital on March 14, 1913, I have shown that the resection of the middle portion of the esophagus for carcinoma is possible.

The patient, a woman, 07 years old, had a carcinoma of the esophagus beginning a little above the lower border of the arch of the aorta and extending from there downward for an inch and a half or more. I had performed a gastrostomy. on her some time previously. The difficulties of the ense being known, the problem was to plan the ways and means of overcoming them. It was necessury, first, to afford better access, secondly, to perform more careful dissection of the pneumogastric nerves,

* Rnad nt " meeting of the New York County Medical Soclety, March 24,1013 avoiding rough handling of them and, thirdly, to do away with the danger of leakage from the proximal stump of the esophagus after resection.

I shall not enter into the details of the operation, but simply outline the most important parts of it." Instead of secking access by going through two different intercostal spaces and dissecting off the scapula or by resecting several adjacent ribs, procedures recommended by others, I incised through the whole length of the seventh intercostal space, from the posterior end of which I extended the incision upward by cutting through the angles of the seventh, sixth, fifth and fourth ribs, which gave a much better exposure and is far simpler. The greater ease of access enabled me to dissect the pneumogastric nerves more carefully, and, to my great satisfaction, the pulse never wavered during this procedure, remaining between 93 and 96 . The dreaded vagus collapse had therefore been safely avoided. The great difficulty of dissecting that part of the esophagus which passes behind the arch of the aorta was overcome by ligating a number of the thoracic branches of the norta and lifting it forward. Lnst, but perhaps most important, to avoid the danger of Ieaknye from the upper stump of the esophagus, I eliminated the esophagus from the pleural cavity altogether. This was done by dissecting the organ loose from its attachments all the way up to the neck and bringing it out through an incision at the anterior border of the left sternocleidomastoid muscle. Thus the pleural envity could not possibly become infected from that source.

The thorax was closed without drainage. The patient made a good recovery. Some of the stitches were removed on the fourth day; the remainder were removed on the seventh day, when the wound proved to be completely closed. Pulse, respiration, and temperature had become normal by the fifth day.

Thirty-two years ago the first successful resection of the stomach for"carcinoma was performed by Billroth. It took a very long time before the operation became popular; now its performance is by no means infrequent.

The operation for carcinoma of the esophagus, I feel certain, will gain friends very quickly, now that the way has been shown for its successful management. The details of the operation will be published presently. The most important thing to consider is that safety depends to a great degree on early diagnosis and early operation, and we must not forget that even very slight difficulty in swallowing may be due to cancer of the esophagus which requires operation. In the light of the success which attended this new method of attacking the disease, it becomes our evident duty to advise operation at once, and thus we shall have the satisfaction of saving the lives of many who otherwise would have been doomed to succumb to their affliction.

1021 Madison Avenue.

\section{SUCCLSSFUL TRANSPLANTATION OF GRAFT WITH- OUT PEIRIOSTEUM}

Horace G. Wetherir.L, M.D., Denver

Since the pullication of my paper, "The Growth, the Death and the Regeneration of Bone,"' the question has been raised whether or not the ultimate result in my second case, in which the graft was transplanted without periosteum, was satis. factory.

I have been reminded that few attempts have been made to transplant grafts on masse in human beings, without periosteum, and that of these many have failed. It has been pointed out that a roentgenogram made four weeks nfter

1. Anesthesin was given by trachenl Insuflation according to the Meltzer-Auer method.

1. Wetherill, IIorace (i. : The Growth, the Death and the Regen eration of Bone, THe Jounis A. M. A., March 29, 1013, p. OS3. 